\title{
Sistem Informasi Penjualan Tiket Pesawat Pada PT. Pesona Liburan Sumatera Menggunakan Metode Prototype
}

\section{Article Info \\ Article history:}

Received Feb 26, 2020

Revised Mar 18, 2020

Accepted Apr 01, 2020

\section{Keywords:}

Information Systems, Sales, Airline Tickets, Prototype Methods.

\begin{abstract}
Transportation services and airfare sales services to all airlines as a whole have used the information system as a means of corporate brand promotion and have obtained results in accordance with the expected level of ticket sales that are increasing every month. But the information system is only limited to the promotion of air ticket sales, while for the creation of air ticket sales reports still using manual means, this causes a buildup of paper, making it very difficult to find the required documents. Based on the description above, this research was conducted to design and build an information system for air ticket sales at PT. Pesona Libur Sumatra by utilizing the prototype method using the visual program language of studio 2015 equipped with SQL Server 2008 database.
\end{abstract}

This is an open access article under the CC BY-SA license.

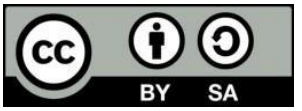

Corresponding Author:

Putri Permata Sari

Politeknik Ganesha Medan, Manajemen Informasi, Medan, Indonesia

Email Address: putri.permatasari@gmail.com

(C) 2020 The Author: Published by. Cattleya Darmaya Fortuna

\section{Pendahuluan}

Pada era sekarang ini perkembangan ilmu pengetahuan dan teknologi semakin pesat dan canggih terutama dalam penggunaan komputer yang hampir seluruhnya masuk dan memiliki pengaruh yang cukup besar bagi kehidupan manusia dengan komputer [1], manusia dapat menyelesaikan tugas dengan cepat dan akurat [2]. Dalam penggunaan jasa perjalanan wisata, salah satu langkah untuk mempermudah operasional sistem adalah melalui pemanfaatan komputer dengan membuat sistem informasi yang dapat menyimpan data secara lengkap dan cepat[3]. Begitu pula halnya dengan PT. Pesona Sumatera Holidays, merupakan salah satu biro perjalanan wisata yang bergerak di bidang jasa[4]. PT. Pesona Hari Libur Sumatera dalam pembuatan laporan penjualan masih menggunakan cara manual, dan hal ini dinilai tidak efektif dan tidak efisien jika dilihat dari segi waktu dan tenaga,Penelitian sebelumnya dilakukan pada perusahaan pada tahun 2015 Asia Wisata Tour \& Travel Yogyakarta sebagai biro perjalanan yang salah satu kegiatannya melayani tiket pesawat yang sudah memiliki sistem reservasi 


\section{Putri Permata Sari}

doi.org/10.54209/jatilima.v2i1.129

online untuk beberapa maskapai domestik dan internasional [5]. Dengan adanya layanan ini memberikan kemudahan dalam proses penjualan tiket kepada konsumen [6]. Di Asia Wisata Tour \& Travel sudah memiliki sistem yang terintegrasi sehingga dapat melakukan pengecekan harga tiket pesawat, serta mempermudah proses penjualan [7]. Namun masih menggunakan sistem manual untuk laporan penjualan tiket [8]. Sistem Informasi adalah suatu organisasi yang mempertemukan kebutuhan pemrosesan transaksi, mendukung operasi manajerial, dan kegiatan strategis suatu organisasi dan menyediakan pihak luar tertentu dengan laporan-laporan yang diperlukan [9]. Sedangkan penjualan adalah suatu kegiatan yang dilakukan oleh manusia dengan tujuan untuk memuaskan kebutuhan dan keinginan pelanggan, melalui suatu proses pertukaran dan kepada pihak-pihak yang berkepentingan dengan perusahaan [10]. Penjelasan diatas bisa jadi disimpulkan bahwa sistem informasi penjualan adalah sekelompok orang yang saling bertemu untuk melakukan kegiatan dengan tujuan memenuhi kebutuhan [11] melalui proses pertukaran barang dan jasa oleh pihak yang berkepentingan melalui transaksi [12]. Berdasarkan permasalahan di atas, PT. Pesona Sumatra Holidays Tour \& Travel Medan membutuhkan sistem informasi yang terkomputerisasi melalui penggunaan metode prototype sehingga dapat disesuaikan dengan kebutuhannya dan dapat membantu menyampaikan informasi secara lebih cepat dan akurat dalam mengolah data penjualan tiket [13]. Metode prototipe adalah proses pembuatan model sederhana melalui perangkat lunak yang memungkinkan pengguna memiliki gambaran dasar program dan melakukan pengujian awal[14].

\section{Metode}

Metode prototype merupakan salah satu metode yang digunakan dalam penelitian ini untuk menghasilkan sebuah aplikasi sistem informasi perusahaan dalam membantu pembuatan laporan penjualan tiket pesawat melalui beberapa tahapan yang harus dilakukan sehingga nantinya akan memberikan hasil yang sesuai dengan yang diharapkan. penjelasan pada bab pendahuluan [15]. Langkah-langkah penelitian adalah sebagai berikut tahapan penelitian yang harus dilakukan:

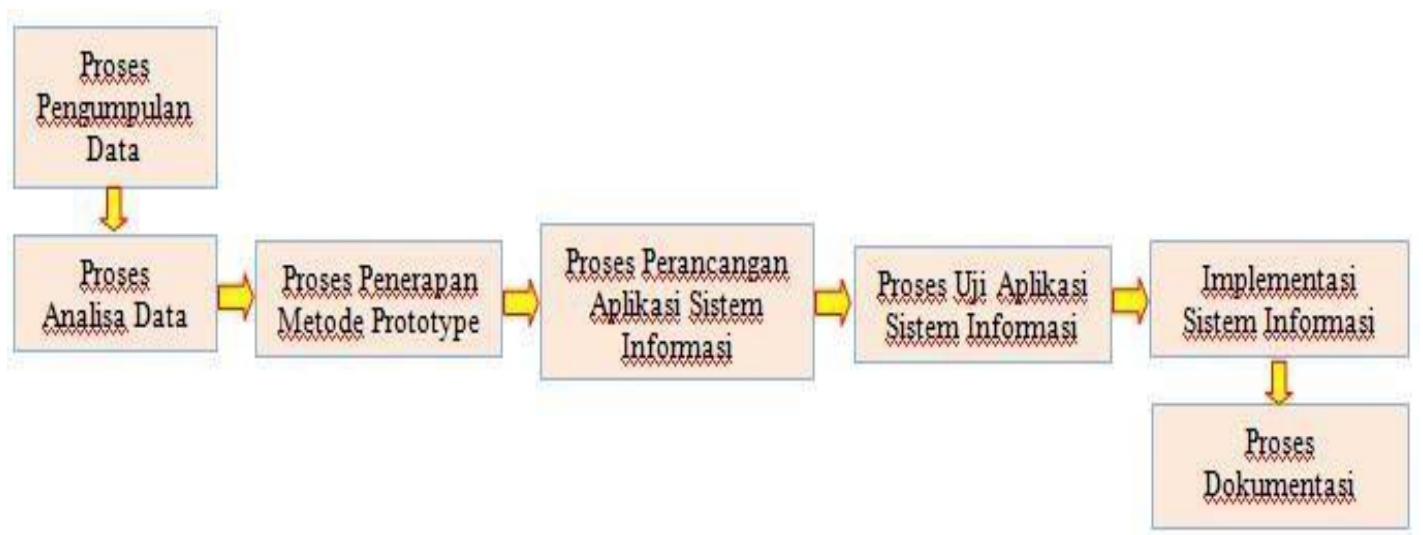

Gambar 1. Tahapan Penelitian

Deskripsi tahapan penelitian:

1. Proses Pengumpulan Data : berfungsi untuk memperoleh sejumlah informasi yang dibutuhkan dalam penelitian agar tujuan penelitian dapat tercapai. 


\section{Putri Permata Sari}

doi.org/10.54209/jatilima.v2i1.129

2. Proses Analisis Data : berfungsi untuk menjelaskan data yang digunakan dalam penelitian sehingga mudah untuk dipahami.

3. Metode Prototype Application Process : berfungsi untuk membantu proses pembuatan laporan penjualan tiket pesawat agar lebih efektif dan efisien.

4. Proses Perancangan Aplikasi Sistem Informasi : berfungsi sebagai database server utama yang akan mengatur seluruh proses penyimpanan data dan transaksi yang akan dilakukan melalui aplikasi.

5. Proses Pengujian Aplikasi Sistem Informasi : berfungsi untuk mendeteksi kondisi aplikasi (software) yang dirancang dari proses sebelum pengujian sampai setelah pengujian, sehingga terlihat jika masih terdapat cacat produk (debug) melalui evaluasi terhadap fitur-fitur yang terdapat pada aplikasi .

6. Implementasi Sistem Informasi : berfungsi untuk menjalankan sistem baru melalui aplikasi yang telah dirancang sesuai kebutuhan perusahaan dengan memberikan pelatihan dan bimbingan seperlunya.

7. Proses Dokumentasi : berfungsi untuk memperoleh sekumpulan data melalui aplikasi yang telah dirancang sehingga dapat dibuat dalam bentuk laporan.

\section{Menjalankan Analisis Sistem}

Analisis sistem merupakan suatu proses yang dapat digunakan untuk mengetahui permasalahan yang dihadapi. Sistem yang berjalan dapat didefinisikan sebagai menggambar, merencanakan dan membuat sketsa atau menyusun beberapa elemen yang terpisah menjadi satu kesatuan yang utuh dan berfungsi [7].

\section{Diagram konteks}

Diagram konteks merupakan level tertinggi dalam sebuah diagram alir data dan hanya membuat satu proses yang menunjukkan sistem secara keseluruhan [8].

\section{Diagram Aliran Data (DFD)}

Data Flow Diagram (DFD) merupakan alat untuk menggambarkan arus informasi dan transformasi data yang dimulai dari input data hingga menghasilkan data output [9]. Menurut [10] terdapat 4 (empat) proses pada DFD Level 0 yang menjelaskan aliran data yang saling berhubungan dengan penelitian yang dilakukan:

1. Masukkan data pelanggan agar dapat disimpan.

2. Cetak data pelanggan dan laporkan ke perusahaan.

3. Konfirmasi penerimaan transaksi tiket yang dilakukan oleh perusahaan.

4. Konfirmasi penerimaan acc yang dilakukan oleh operator kepada pelanggan.

\section{Hasil dan Pembahasan}

Analisis sistem ini dibuat untuk memudahkan pemecahan masalah dengan analisis yang baik yang akan mempengaruhi kualitas penelitian ini. Penjualan tiket pesawat dibuat dengan menggunakan sistem yang akan memudahkan untuk menggambarkan sistem yang sedang berjalan untuk dapat dibandingkan dengan sistem yang akan dirancang pada gambar berikut: 


\section{Putri Permata Sari}

doi.org/10.54209/jatilima.v2i1.129

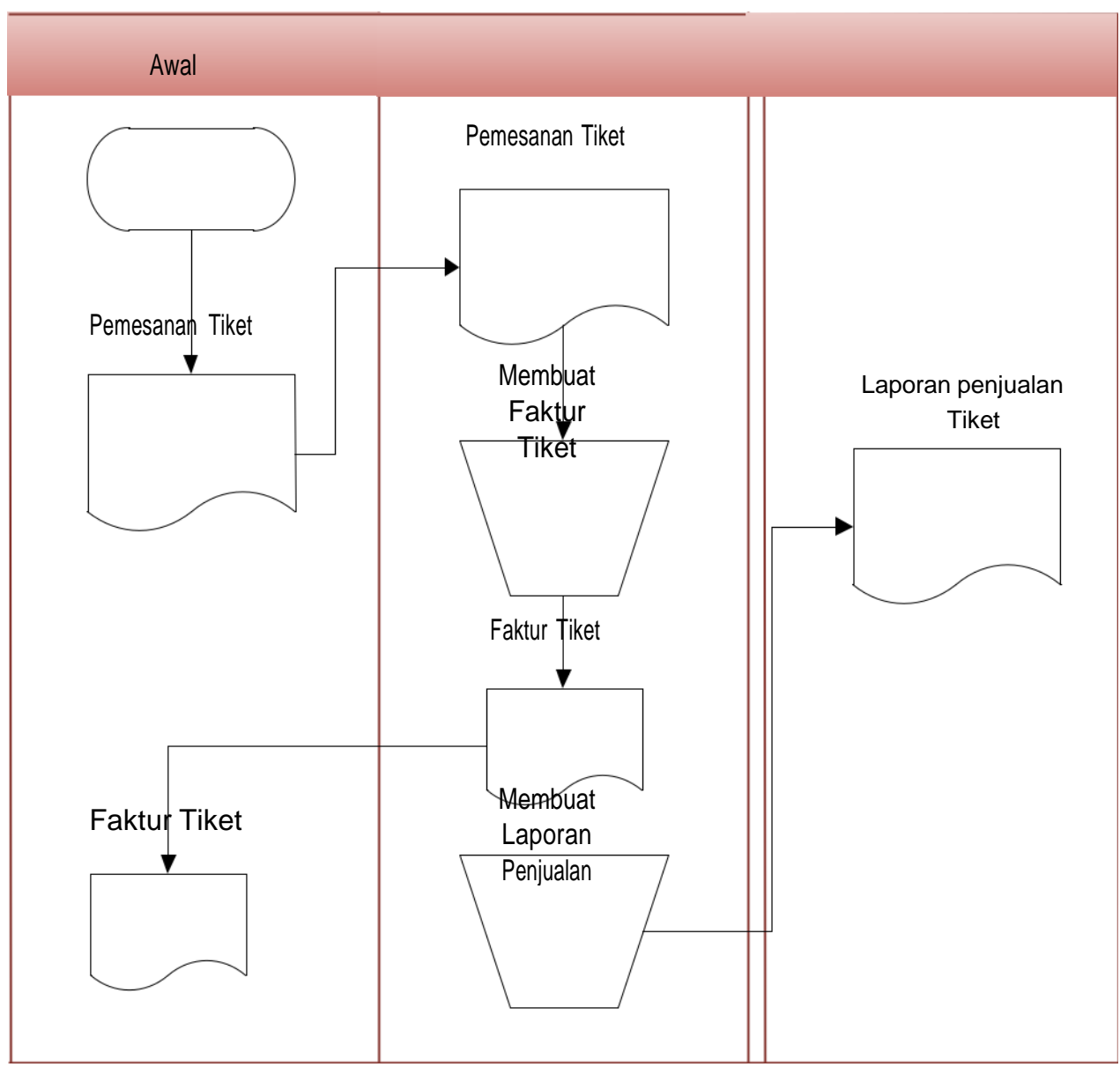

Gambar 2. Flowmap Sistem Saat Ini

Deskripsi peta alur:

1. Pelanggan : Pelanggan mengirimkan data pesanan dan kemudian diinformasikan ke tiket.

2. Tiket $\quad$ : Proses ticketing adalah sebagai berikut:

a. Pelanggan datang langsung atau memesan tiket melalui telepon ke bagian ticketing PT. Pesona Liburan Sumatera.

b. Bagian ticketing mengecek ketersediaan tiket, jika ada maka transaksi dilanjutkan.

c. Pelanggan mengirimkan data pelanggan.

d. Bagian ticketing mengeluarkan tiket pesawat.

e. Pengunjung mendapatkan invoice tiket dengan catatan bahwa pelanggan telah melakukan pembayaran tunai.

f. Kasir membuat 2 rangkap laporan, 1 sebagai arsip dan 1 lagi diserahkan kepada direktur.

3. Direktur : Sebagai laporan tagihan tiket yang dikumpulkan dan dicatat di bukukemudian diserahkan kepada direktur.

Diagram konteks berdasarkan permasalahan dalam penanganan tiket dijelaskan pada 


\section{Putri Permata Sari}

doi.org/10.54209/jatilima.v2i1.129

gambar di bawah ini:

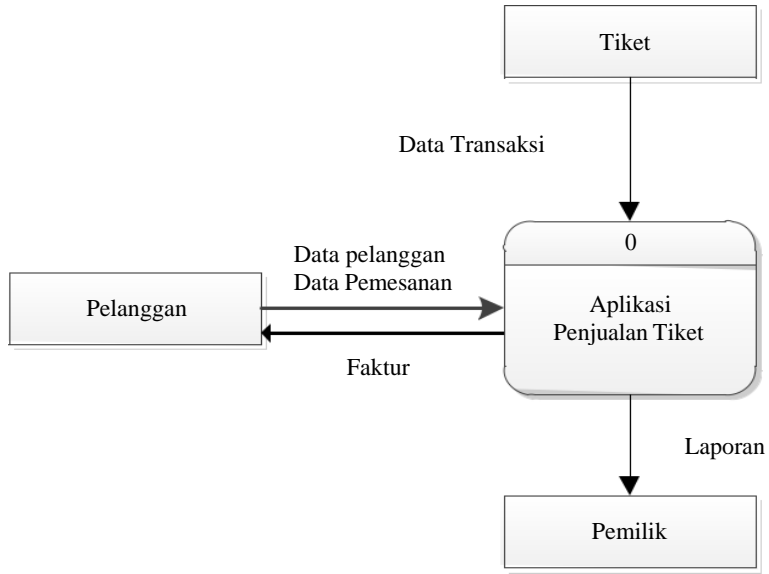

Gambar 3. Diagram Konteks Sistem Informasi Data Penjualan Tiket

\section{Deskripsi diagram konteks:}

Pelanggan menyampaikan data pelanggan dan data pesanan yang kemudian diolah ke dalam aplikasi penjualan tiket yang dilakukan oleh pihak ticketing, kemudian dari transaksi yang tersimpan di database dihasilkan beberapa jenis laporan yang akan disampaikan kepada pemilik.Diagram alir data digambarkan berdasarkan permasalahan dalam penanganan tiket yang dijelaskan pada gambar di bawah ini:

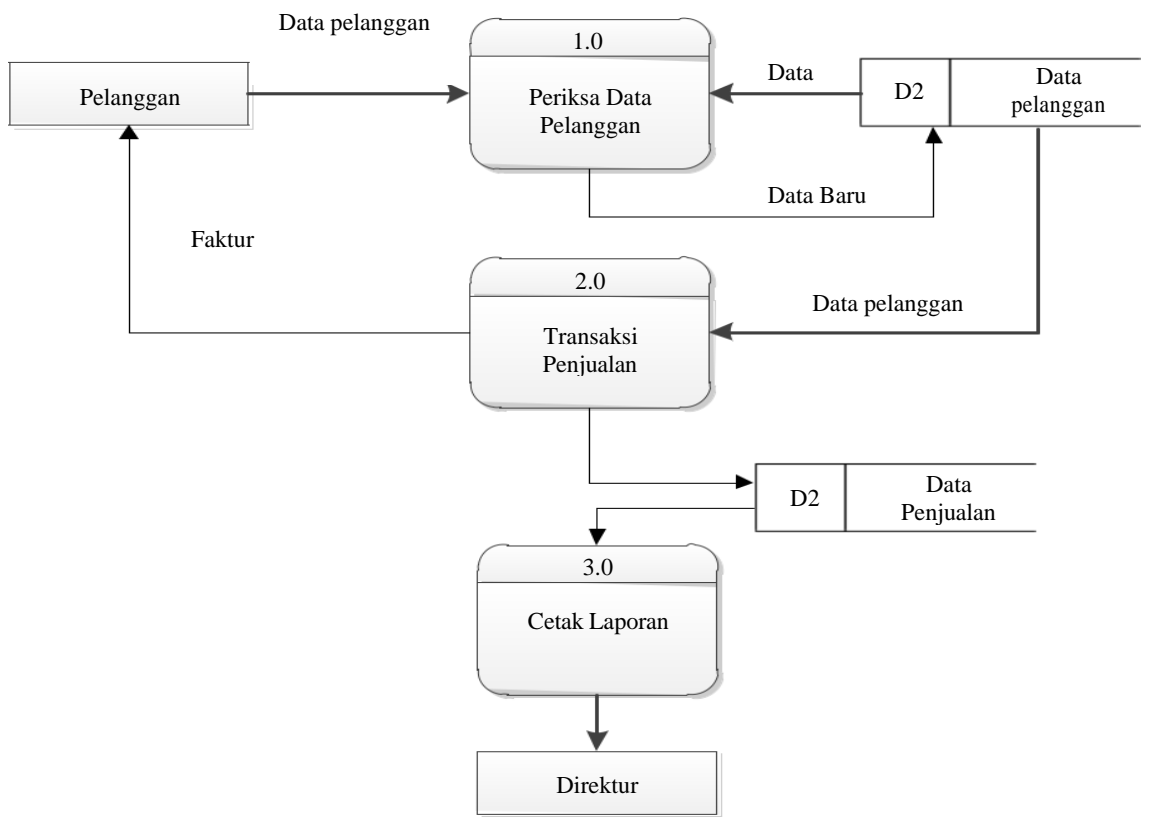

Gambar 4. Sistem DFD

\section{Deskripsi DFD:}

Pelanggan harus melapor terlebih dahulu ke bagian ticketing dan menyerahkan data pelanggan. Kemudian aplikasi melakukan pengecekan ketersediaan data pelanggan, jika data pelanggan belum pernah tersimpan di database aplikasi maka data pelanggan baru 


\section{Putri Permata Sari}

doi.org/10.54209/jatilima.v2i1.129

akan tersimpan di sistem. Dari data pelanggan yang telah disimpan, dilakukan transaksi penjualan. Kemudian invoice dan tiket diberikan kepada pelanggan. Selanjutnya hasil laporan data penjualan tiket akan diberikan kepada Direktur.

\section{Implementasi Sistem}

\section{Sebuah. Formulir Data Maskapai}

Laporan input pelanggan disediakan dalam ukuran kertas A4 dengan orientasi potret yang dapat dicetak atau disimpan sebagai dokumen digital dalam bentuk file PDF, Word, dan Excel.

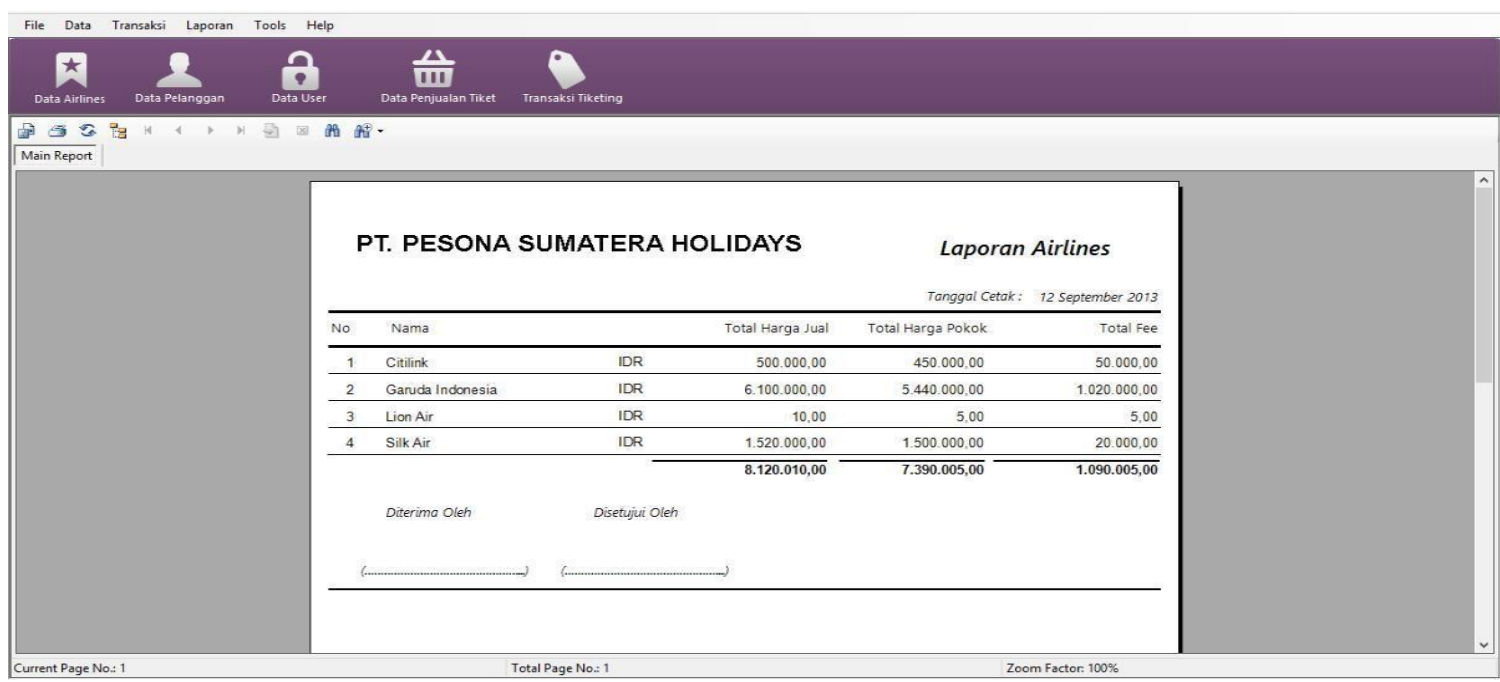

Gambar 5. Laporan Masukan Pelanggan

\section{B. Formulir Data Pelanggan}

Laporan data pelanggan disediakan dalam ukuran kertas A4 dengan orientasi potret yang dapat dicetak atau disimpan sebagai dokumen digital dalam bentuk file PDF, Word, dan Excel.

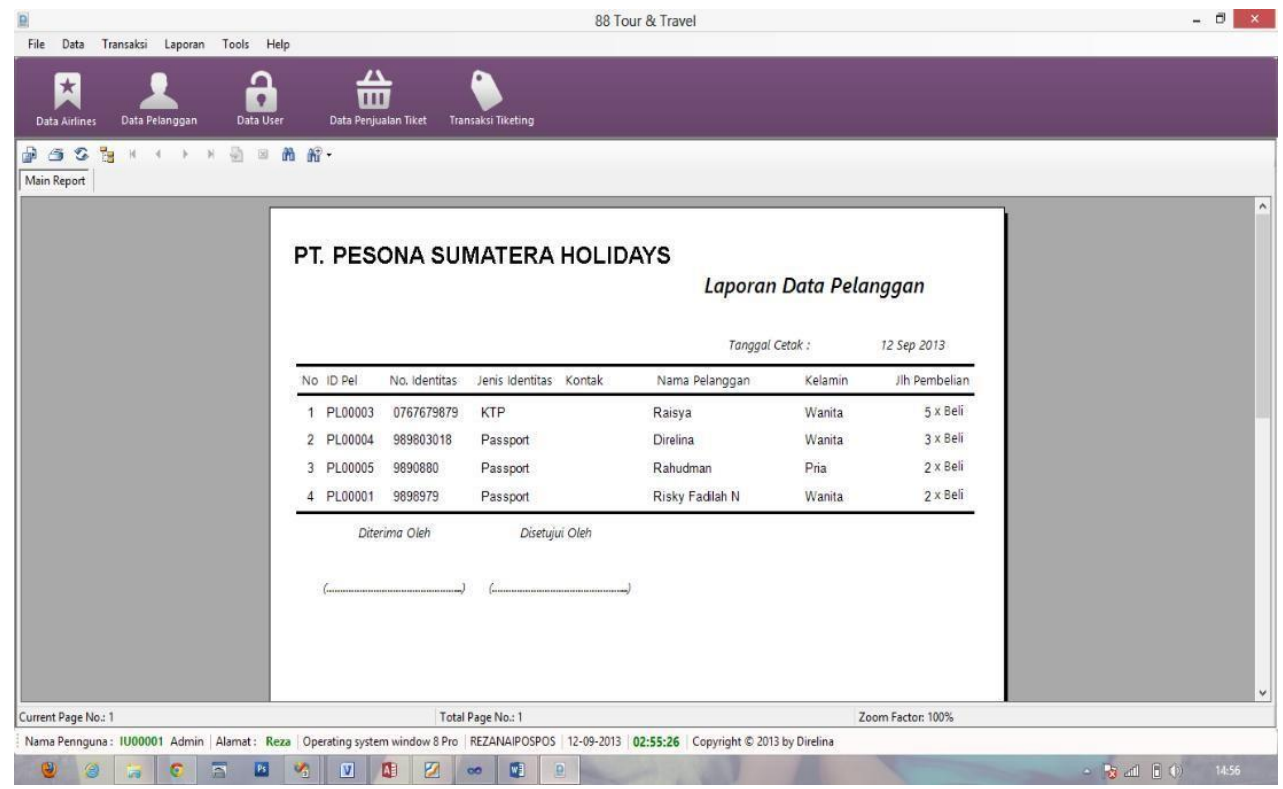

Gambar 6. Laporan Data Pelanggan 


\section{Putri Permata Sari}

doi.org/10.54209/jatilima.v2i1.129

\section{Formulir Data Pengguna}

Formulir masukanfungsi pelanggan adalah menambah data pelanggan baru, atau mengubah data pelanggan lama dengan fungsi masing-masing tombol sebagai berikut:

1. Tombol Tambah digunakan untuk mengaktifkan perintah tambah data.

2. Tombol Simpan digunakan untuk menyimpan data ke dalam database

3. Tombol Hapus digunakan untuk menghapus data dalam database

4. Tombol Batal digunakan untuk membatalkan input

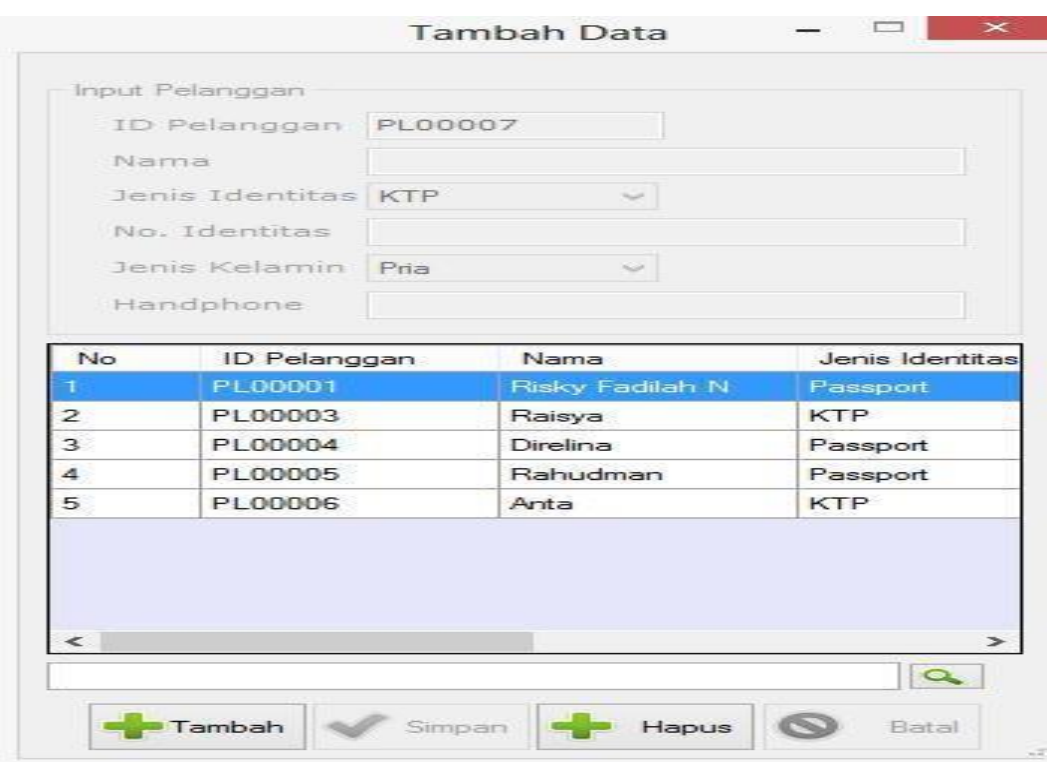

Gambar 7. Laporan Data Pengguna

\section{Formulir Data Penjualan}

Laporan Penjualan Tiket menampilkan data penjualan secara garis besar atau dengan kata lain hanya menampilkan total nominal transaksi penjualan yang terjadi berdasarkan setiap nomor invoice.

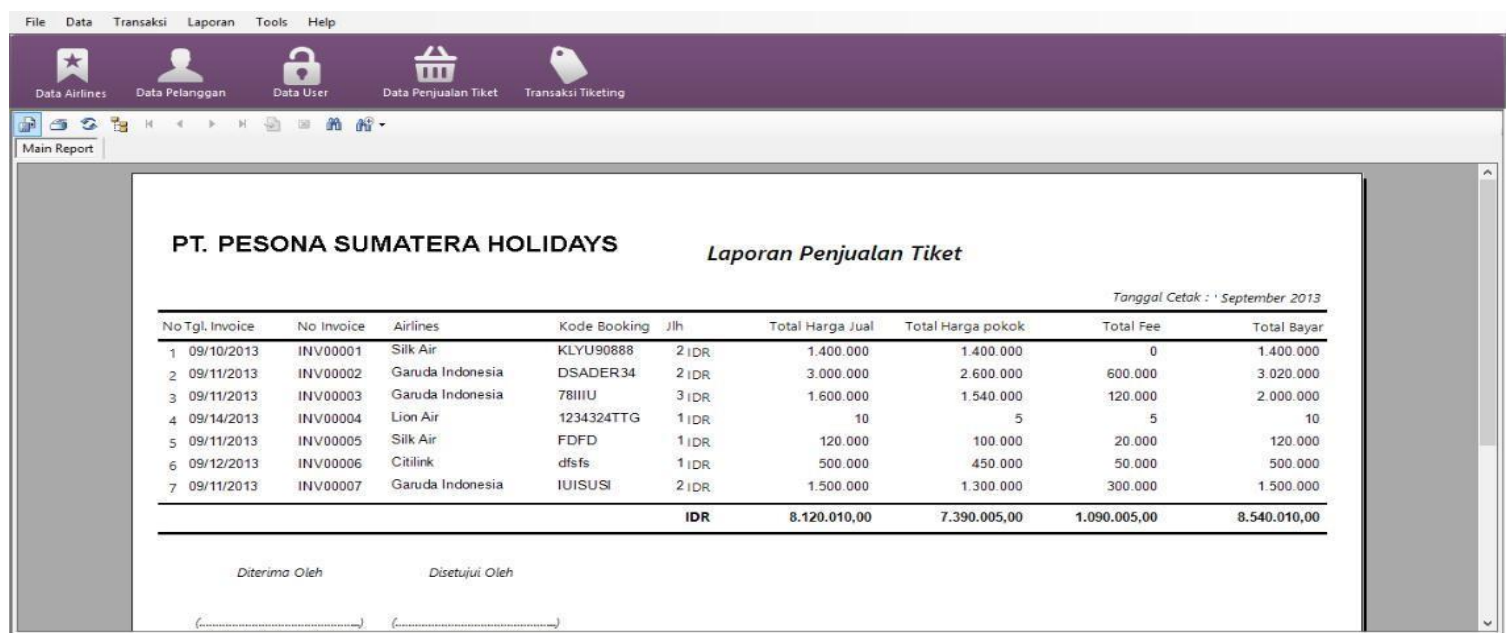

Gambar 8. Laporan Penjualan Tiket Pesawat 


\section{Putri Permata Sari}

doi.org/10.54209/jatilima.v2i1.129

\section{E. Formulir dan Laporan Transaksi Tiket}

Membentuk fungsi ticketing adalah untuk melakukan transaksi ticketing bagi pelanggan yang membeli tiket. Form penjualan ini memberikan nomor invoice secara otomatis dan menginput detail pembelian langsung ke kolom datagridview.

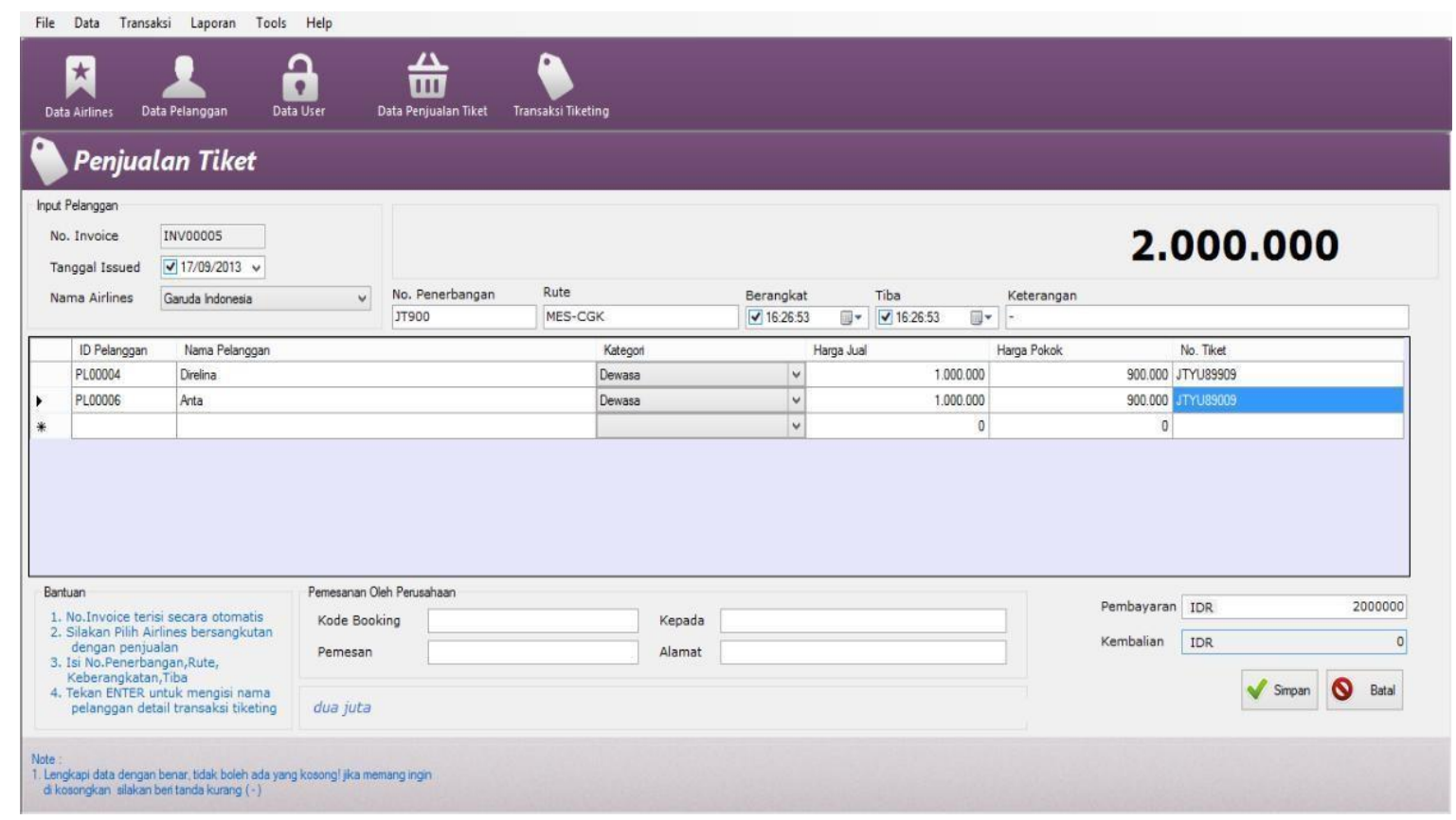

Gambar 9. Laporan Transaksi Tiket

Faktur merupakan bukti transaksi yang diserahkan kepada nasabah. Faktur dapat dicetak dengan ukuran kertas A5 atau disimpan sebagai file dalam format PDF, Word dan Excel.

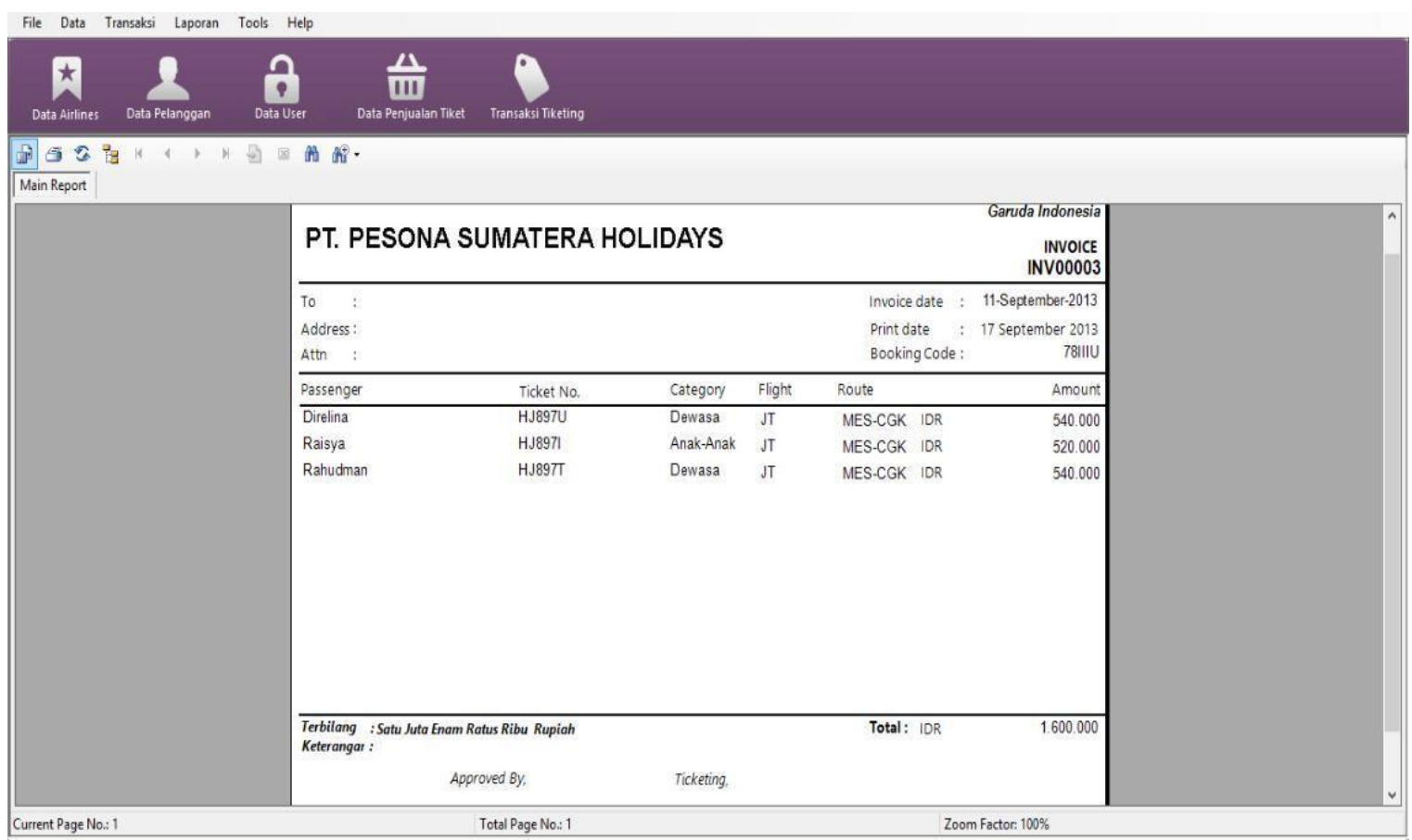

Gambar 10. Laporan Faktur 


\section{Putri Permata Sari}

doi.org/10.54209/jatilima.v2i1.129

\section{Kesimpulan}

Dari analisis dan pembahasan kasus di atas, dapat disimpulkan bahwa: Perancangan sistem informasi ini sangat bermanfaat bagi perusahaan PT. Pesona Sumatera Holidays karena dapat membantu dalam mempermudah proses pembuatan laporan penjualan tiket pesawat secara cepat dan akurat. Perancangan sistem informasi ini ditentukan dari beberapa tahapan penelitian yang telah ditentukan agar mendapatkan hasil yang diinginkan. Metode prototype sangat tepat digunakan dalam penelitian ini karena metode tersebut merupakan proses dari mengembangkan model atau desain ke dalam sistem komputerisasi.

\section{Referensi}

[1] I. Ananda and E. Zuraidah, "Perancangan Sistem Informasi Penjualan Barang Pada PT Asia Truk Pratama Jakarta,” J. Inform., vol. 6, no. 2, 2019, doi: 10.31311/ji.v6i2.6248.

[2] E. Damayanti, "Sistem Informasi Penjualan Obat Pertanian Berbasis Web pada Toko BUTANI Blora," Walisongo J. Inf. Technol., vol. 1, no. 2, 2019, doi: 10.21580/wjit.2019.1.2.4520.

[3] H. Nur, "Penggunaan Metode Waterfall Dalam Rancang Bangun Sistem Informasi Penjualan," Gener. J., vol. 3, no. 1, 2019, doi: 10.29407/gj.v3i1.12642.

[4] H. D. Wahyuningsih, P. Paryanta, and H. C. Winoto, "Sistem Informasi Penjualan Barang pada Toko Candra Berbasis Android," Go Infotech J. Ilm. STMIK AUB, vol. 25, no. 1, 2019, doi: 10.36309/goi.v25i1.99.

[5] E. Sasmita Susanto, Y. Karisma, and S. Isnaeni, "SISTEM INFORMASI PENJUALAN PADA TOKO JILBAB RJS KABUPATEN SUMBAWA BERBASIS WEB," J. Inform. Teknol. dan Sains, vol. 1, no. 2, 2019, doi: 10.51401/jinteks.v1i2.414.

[6] M. Fadhilurrahman and A. Al-Anis, "Sistem Informasi Tiket Kapal Ferri Dengan Menggunakan Sistem Antrian di Pelabuhan Jangkar Berbasis Web," Cyber-Techn, vol. 13 , no. $01,2018$.

[7] M. Rizky, Y. Sugiyani, and Harsiti, "Sistem Informasi Pemesanan E-Tiket Kapal Laut pada PT. Bandar Bakau Jaya," Sist. Inf. Pemesanan E-Tiket Kapal Laut pada PT. Bandar Bakau Jaya, no. November, 2018.

[8] K. Widyatmoko and E. E. Rumteh, "Sistem Informasi Pemesanan Tiket Pada Floo Tour and Travel Berbasis Web," J., vol. 3, no. 2, 2018.

[9] M. F. H. Mubarok, A. R. T. Hayati Ririd, and N. Santoso, "RANCANG BANGUN SISTEM INFORMASI PENJUALAN TIKET KAPAL EXPRESS BAHARI 1C GRESIK - BAWEAN BERBASIS WEB,” J. Inform. Polinema, vol. 1, no. 2, 2017, doi: 10.33795/jip.v1i2.98.

[10] Setiyawan, "Sistem Informasi Penjualan Tiket Berbasis Multiuser Pada Semawis Water Park Di Semarang," J. Chem. Inf. Model., vol. 53, no. 9, 2017.

[11] R. F. Ahmad and N. Hasti, "SISTEM INFORMASI PENJUALAN SANDAL BERBASIS WEB," J. Teknol. dan Inf., vol. 8, no. 1, 2018, doi: 10.34010/jati.v8i1.911.

[12] G. P. Wulandari and others, "Implementasi E-Commerce Pada Penjualan Tiket Online Berbasis Rail Ticket System Di Pt Kereta Api Indonesia (Persero) Daerah Operasi 8 Surabaya Gubeng."

[13] P. Perdana, "PERANCANGAN SISTEM INFORMASI PENJUALAN TIKET BUS BERBASIS WEB," UBSI, 2019.

[14] H. Priyambudi, "Pengertian Metode Prototype, Tahapan dan Kelebihan Metode Prototype," 29 Novemb. 2017, 2017.

[15] D. A. Punkastyo, "Perancangan Aplikasi Tutorial Jurus Dasar Beladiri Cimande 


\section{Putri Permata Sari}

doi.org/10.54209/jatilima.v2i1.129

Menggunakan Metode Prototype," J. Inform. Univ. Pamulang, vol. 3, no. 2, 2018, doi: 10.32493/informatika.v3i2.1433. 